\title{
Epidemiology and risk factors of chronic obstructive pulmonary disease in Suzhou: a population-based cross-sectional study
}

\author{
Xiaopei Yan", Li Xu", Baoyu Shi, Hui Wang, Xiao Xu*, Guopeng Xu* \\ Department of Pulmonary and Critical Care Medicine, The Affiliated Suzhou Hospital of Nanjing Medical University, Suzhou Municipal Hospital, \\ Suzhou, China \\ Contributions: (I) Conception and design: All authors; (II) Administrative support: All authors; (III) Provision of study materials or patients: All \\ authors; (IV) Collection and assembly of data: All authors; (V) Data analysis and interpretation: All authors; (VI) Manuscript writing: All authors; (VII) \\ Final approval of manuscript: All authors. \\ ${ }^{\#}$ These authors contributed equally to this work. \\ *These authors contributed equally to this work. \\ Correspondence to: Xiao Xu; Guopeng Xu. Department of Pulmonary and Critical Care Medicine, The Affiliated Suzhou Hospital of Nanjing Medical \\ University, Suzhou Municipal Hospital, 26 Daoqian Road, Suzhou, China. Email: xuxiao81179@163.com; xuguopeng2046@163.com.
}

\begin{abstract}
Background: The prevalence of chronic obstructive pulmonary disease (COPD) in Suzhou remains still unknown. The aim of this study was to quantify the disease burden and assess the risk factors of COPD.

Methods: This was a population-based, cross-sectional study of adults aged 40 years and older in Suzhou. A total of 4,864 adults were identified from June 2018 to December 2018 and 4,725 adults were finally recruited. Subjects underwent post-bronchodilator spirometry and were diagnosed according to the 2018 Global Initiative for Chronic Obstructive Lung Disease (GOLD).

Results: The data from 4,725 adults were ultimately included in the final analysis. The overall prevalence of COPD in subjects aged 40 and older was $12.4 \%$, while it was $12.3 \%$ in men and $12.5 \%$ in women. Risk factors identified by multivariable logistic analysis were age $(\mathrm{P}<0.05$, OR $=2.29,95 \% \mathrm{CI}, 1.83-2.88)$ and underweight $\left(\mathrm{BMI}<18.5 \mathrm{~kg} / \mathrm{m}^{2}\right)(\mathrm{P}<0.05$, OR $=1.57,95 \% \mathrm{CI}, 1.01-2.44)$. COPD patients also displayed weaker grip strength $(\mathrm{P}<0.001)$. Approximately half $(50.7 \%)$ the COPD patients were asymptomatic, and compared with asymptomatic COPD patients, symptomatic COPD patients were older (69.5 vs. 67.2, $\mathrm{P}<0.05)$, smoked more frequently (12.1 vs. 7.1 pack year, $\mathrm{P}<0.05$ ), had a more severe GOLD stage (stage I $27.0 \%$ vs. $39.4 \%$, stage II $50.2 \%$ vs. $46.8 \%$, stage III $17.0 \%$ vs. $11.1 \%$, stage IV $5.8 \%$ vs. $2.7 \%, \mathrm{P}<0.05)$, and a worse lung function index $\left(\mathrm{FEV}_{1}, \mathrm{FVC}, \mathrm{PEF}, \mathrm{FEF}_{25}, \mathrm{FEF}_{50}, \mathrm{FEF}_{75}, \mathrm{FEF}_{2575}\right)(\mathrm{P}<0.05)$.

Conclusions: COPD was found to be highly prevalent in adults aged 40 years and older in Suzhou. Age and underweight were major risk factors of COPD. Half of the COPD patients were asymptomatic, and displayed decreased lung function upon the onset of respiratory symptoms. Therefore, spirometry screening is essential for the early detection and management of COPD.
\end{abstract}

Keywords: Chronic obstructive pulmonary disease (COPD); epidemiology; risk factors

Submitted Apr 13, 2020. Accepted for publication Sep 14, 2020.

doi: $10.21037 /$ jtd-20-1616

View this article at: http://dx.doi.org/10.21037/jtd-20-1616

\section{Introduction}

Chronic obstructive pulmonary disease (COPD) is a common, preventable, and treatable disease that is characterized by persistent respiratory symptoms and airflow limitation (1). The global prevalence of COPD in people aged 40 years or older is estimated to be $11.7 \%$ (2), while it is $13.7 \%$ in China (3). The social burden, mortality, and disabilities attributed to COPD is reflected in its ranking 
as the sixth and fourth leading cause of disability-adjusted life years (DALY) globally and China, respectively (4). The prevalence of COPD across China varies greatly, which is partly due to the differing levels of exposure to smoke, ambient air pollution and socioeconomic factors (5). Economically developed cities have better air quality and longer average lifetime, which may affect the epidemiology of COPD. Suzhou, a city economically representative of most developed cities in eastern China, has not been surveyed in terms of its of COPD prevalence and related risk factors. Thus, the aim of this study was to investigate the epidemiology and risk factors of COPD in Suzhou.

\section{Methods}

\section{Study design and subjects}

A population-based, cross-sectional survey was performed in four communities of Suzhou, representing a population of approximately 1 million people across different geographical regions. In each community, a cluster sampling method was used to randomly select some housing districts. All individuals aged 40 years and older were assessed in these districts. The sample size was calculated based on the number of people in this age group. The study protocol was approved by the ethics review committee of the affiliated Suzhou Hospital of Nanjing Medical University (K2018013). The study was conducted in accordance with the Declaration of Helsinki (as revised in 2013).

\section{Data collection}

Subjects were recruited by phone or home visit. All subjects who agreed to participate were interviewed in community hospitals by medically qualified doctors, delegated to perform informed consent-related duties. All subjects were informed of the purpose, process, benefits and risks of the research, before consenting to screening procedure. All subjects who displayed diseases which affected lung function such as lung cancer, bronchiectasis, cardiovascular disease, or cerebrovascular disease, were excluded. Patients exhibiting failure of spirometry or a history of pulmonary surgery were also excluded. Subjects were asked to complete a standard questionnaire and underwent blood routine testing, blood biochemistry testing, along with post bronchodilator spirometry.

\section{Questionnaire and examinations}

The questionnaire covered the demographic data, potential risk factors of COPD, history of chronic disease and drug use, respiratory symptoms, mMRC and CAT test. Blood routine tests were performed with a XE-5000 blood cell analyzer (Sysmex Corporation, Japan) and blood biochemistry tests were measured using the 7600 automatic biochemical analyzer (HITACHI, Japan). Pulmonary function tests were performed with portable spirometers (Oranger Ltd., Tianjin, China) by appropriately trained clinical research team members on all study subjects. The procedure followed the spirometry standards of the American Thoracic Society (ATS) (6). The bronchial dilator, salbutamol (200 mcg), was administered through a $500 \mathrm{~mL}$ spacer and pulmonary function tests were repeated 15-20 minutes after inhaling if airflow limitation was detected in the first pulmonary function test. The diagnostic criteria for COPD and disease severity was based on the 2018 Global Initiative for Chronic Obstructive Lung Disease (GOLD) (1), which defines COPD as patients with postbronchodilator FEV1/FVC $<70 \%$ and delineates severity in the following stages: GOLD stage I (mild), $\geq 80 \%$ predicted; GOLD stage II (moderate), $\geq 50 \%$ to $<80 \%$ predicted; GOLD stage III (severe), $\geq 30 \%$ to $<50 \%$ predicted; and GOLD stage IV (very severe), $<30 \%$ predicted.

\section{Statistical analysis}

The categorical variables were gender, smoking status, family history of smoking, occupation exposure, chronic cough and phlegm, breathlessness, hypertension, and diabetes. If there was normal distribution, the differences between these variables were determined by Chi-square tests, otherwise, the Kruskal-Wallis test was used. Age, BMI, smoking pack years, grip strength, blood index and pulmonary function index were treated as continuous variables. If there was normal distribution, the difference between these variables was assessed by independent samples $t$-test and analysis of variance (ANOVA) tests, otherwise, the Kruskal-Wallis test was used. Potential risk factors for COPD were determined with binary or multivariable logistic regression models. All statistical tests were performed with SPSS21.0 (IBM, USA), A P value of less than 0.05 was deemed significant.

\section{Results}

\section{Demographics}

From June 2018 to December 2018, 4,864 subjects (2,242 male and 2,622 female) were identified in the study. After excluding people with diseases that might have influenced 


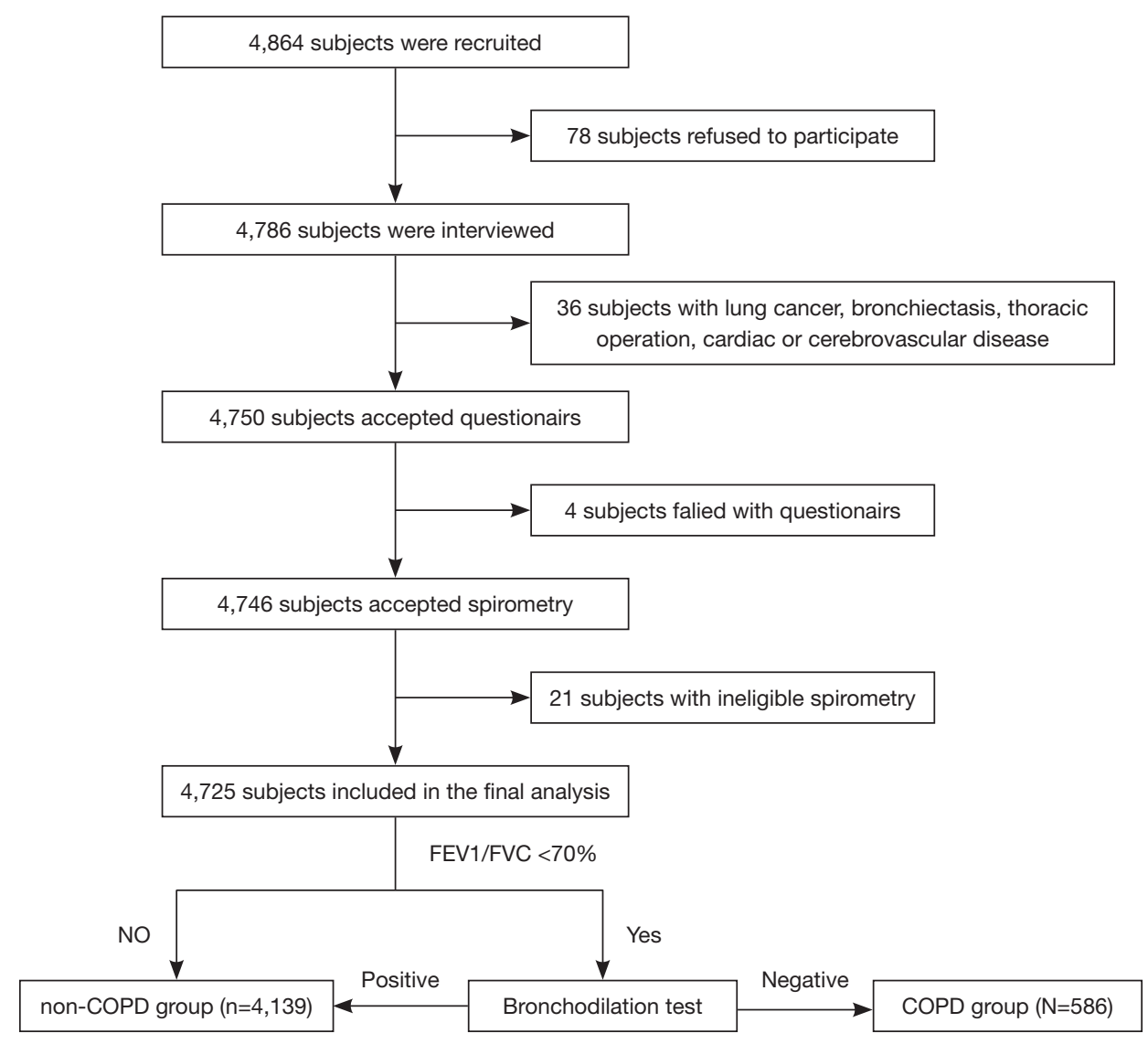

Figure 1 The procedure of subject inclusion. COPD, chronic obstructive pulmonary disease.

the spirometry results, or those without an eligible pulmonary function test, 4,725 subjects $(2,188$ male and 2,537 female) completed the study and were included in the final analysis (Figure 1). The average age of the total population was 62.2 years, and ranged from 40 to 95 years.

\section{Prevalence of COPD}

Based on the COPD diagnostic criteria of 2018 GOLD, the prevalence of COPD in the Suzhou population aged 40 and older was $12.4 \%$. No significant differences were noted in prevalence between men and women (12.3\% vs. $12.5 \%$, $\mathrm{P}>0.05)$. However, the incidence of COPD increased with age, with prevalence rates of $4.6 \%, 6.1 \%, 12.4 \%, 20.4 \%$, and $30.9 \%$ observed among populations aged $40-49,50-59$, $60-69,70-79$ and $\geq 80$, respectively. The proportion of GOLD stages I, II, III and IV was $33.3 \%, 48.4 \%, 14.0 \%$ and $4.3 \%$, respectively. The COPD prevalence was higher in people with hypertension $(13.8 \%$ vs. $11.5 \%, \mathrm{P}<0.05)$, diabetes $(15.7 \%$ vs. $12.0 \%, \mathrm{P}<0.05)$, and a family history of chronic bronchitis $(17.0 \%$ vs. $11.5 \%, \mathrm{P}<0.05)$.

\section{Risk factors of COPD}

The general characteristics and risk factors are listed in Table 1, and grouped according to their COPD status. The average age of COPD group was significantly older than the non-COPD group $(\mathrm{P}<0.001)$, while the COPD group had lower BMI $(\mathrm{P}<0.001)$. Smoking history and degree of exposure was similar between the groups, while family history of chronic bronchitis was more common in the COPD group $(\mathrm{P}<0.001)$. This group also showed more symptoms of chronic cough and phlegm $(\mathrm{P}<0.001)$, along with weaker grip strength $(\mathrm{P}<0.001)$. Furthermore, a combination of hypertension $(\mathrm{P}=0.021)$ and diabetes $(\mathrm{P}=0.015)$ was more common in the COPD group. Hematological analysis revealed higher levels of hemoglobin, hematocrit, mean corpuscular hemoglobin concentration (MCHC), red blood cell count, and serum creatinine in the COPD group $(\mathrm{P}<0.05)$. However, the same 
Table 1 General characteristics between COPD and non-COPD subjects

\begin{tabular}{|c|c|c|c|}
\hline Characteristics & COPD $(n=586)$ & Non-COPD $(n=4,139)$ & $P$ \\
\hline $40-59$ & $107(18.3 \%)$ & $1,802(43.5 \%)$ & \\
\hline $60-79$ & $404(68.9 \%)$ & $2,169(52.4 \%)$ & \\
\hline$\geq 80$ & $75(12.8 \%)$ & $168(4.1 \%)$ & \\
\hline Male & 269 (45.9\%) & $1,919(46.4 \%)$ & \\
\hline Female & 317 (54.1\%) & $2,220(53.6 \%)$ & \\
\hline $\mathrm{BMI}\left(\mathrm{kg} / \mathrm{m}^{2}\right)$ & $23.3 \pm 3.2$ & $24.2 \pm 3.1$ & $<0.001$ \\
\hline$<18.5$ & $31(5.3 \%)$ & $90(2.2 \%)$ & \\
\hline Smoking history & & & 0.403 \\
\hline Never-smoker & $397(67.8 \%)$ & $2,774(67.0 \%)$ & \\
\hline Former smoker & $54(9.2 \%)$ & $330(8.0 \%)$ & \\
\hline Current smoker & $135(23.0 \%)$ & $1,035(25.0 \%)$ & \\
\hline Years of smoking & $11.6 \pm 18.7$ & $10.0 \pm 15.9$ & 0.123 \\
\hline Smoking pack-years & $9.6 \pm 18.8$ & $9.0 \pm 17.2$ & 0.454 \\
\hline 0 & $397 / 584(68.0 \%)$ & 2,775/4,130 (67.2\%) & \\
\hline $0.1-9.9$ & $30 / 584(5.1 \%)$ & $215 / 4,130$ (5.2\%) & \\
\hline Breathlessness & $194(33.1 \%)$ & $1,302(31.5 \%)$ & 0.422 \\
\hline Grip strength (kg) & $26.0 \pm 8.3$ & $29.6 \pm 9.5$ & $<0.001$ \\
\hline Hypertension & $260(44.4 \%)$ & $1,630(39.4 \%)$ & 0.021 \\
\hline Diabetes & $80(13.7 \%)$ & $428(10.3 \%)$ & 0.015 \\
\hline Hemoglobin(g/L) & $136.2 \pm 15.7$ & $138.3 \pm 15.5$ & 0.002 \\
\hline Hematocrit (\%) & $41.5 \pm 4.2$ & $42.0 \pm 4.1$ & 0.004 \\
\hline $\operatorname{MCV}(f L)$ & $93.5 \pm 5.7$ & $92.8 \pm 5.2$ & 0.004 \\
\hline $\mathrm{MCHC}(\mathrm{g} / \mathrm{L})$ & $327.8 \pm 9.9$ & $328.7 \pm 9.9$ & 0.036 \\
\hline Red blood cell count $\left(\times 10^{12} / L\right)$ & $4.46 \pm 0.5$ & $4.55 \pm 0.5$ & 0.001 \\
\hline Monocyte count $\left(\times 10^{9} / \mathrm{L}\right)$ & $0.40 \pm 0.1$ & $0.38 \pm 0.1$ & 0.008 \\
\hline Monocyte percent (\%) & $6.64 \pm 1.7$ & $6.19 \pm 1.6$ & $<0.001$ \\
\hline
\end{tabular}

Table 1 (continued) 
Table 1 (continued)

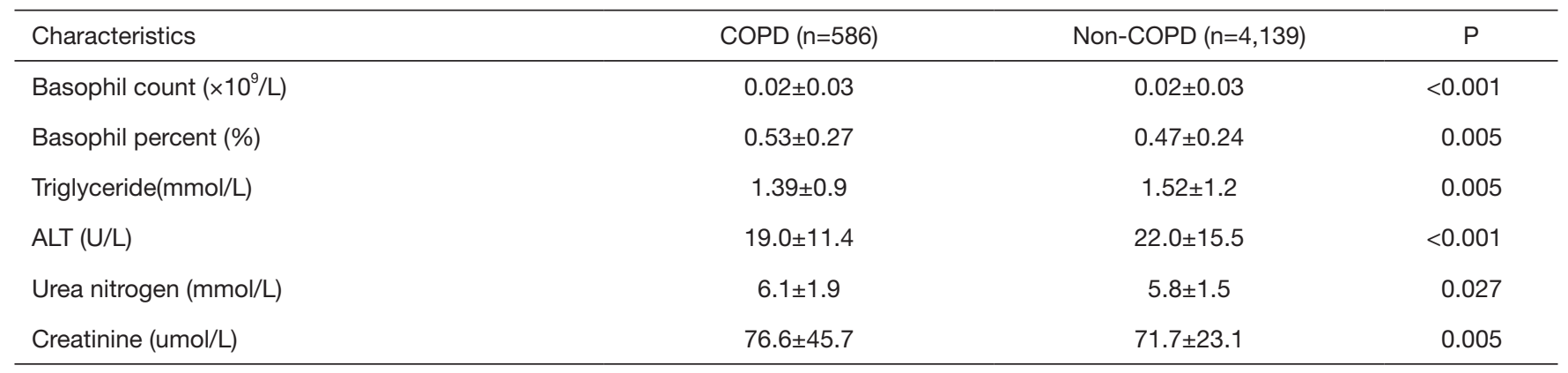

COPD, chronic obstructive pulmonary disease; BMI, body mass index; MCV, mean corpuscular volume; MCHC, mean corpuscular hemoglobin concentration; ALT, alanine transaminase.

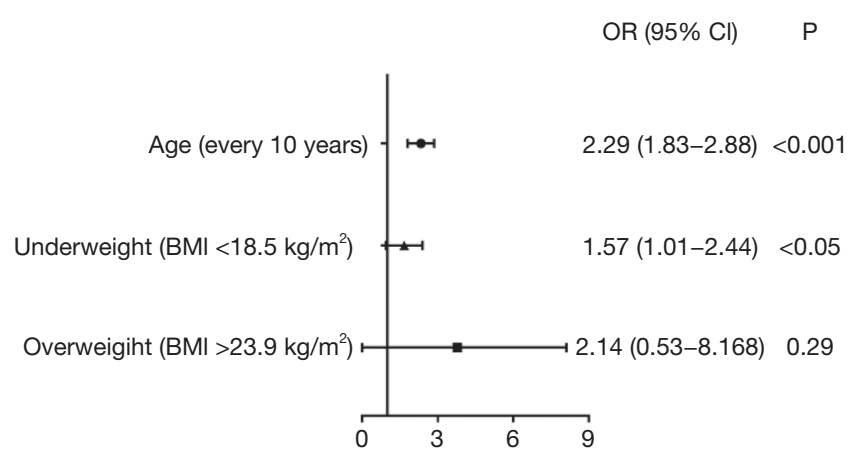

Figure 2 Multivariable logistic regression analysis for risk factors of COPD. After adjustments for gender, older age (every 10 years) and underweight (BMI $<18.5 \mathrm{~kg} / \mathrm{m}^{2}$ ) were found to be independent risk factors of COPD. COPD, chronic obstructive pulmonary disease.

group exhibited lower mean corpuscular volume (MCV), triglyceride, alanine transaminase (ALT) and urea nitrogen $(\mathrm{P}<0.05)$.

Variables of age, gender, BMI, family history of chronic bronchitis, chronic cough and phlegm, grip strength, hypertension, diabetes, hemoglobin, hematocrit, MCV, MCHC, red blood cell count, monocyte count, monocyte percent, basophil count, basophil percent, triglyceride, ALT, urea nitrogen, and creatinine were performed with binary logistic regression analysis. Age, and BMI were independent risk factors for $\mathrm{COPD}(\mathrm{P}<0.05)$. Age was sub-divided on a decade basis for further analysis. Additionally, BMI was further categorized into underweight (BMI $<18.5 \mathrm{~kg} / \mathrm{m}^{2}$ ), normal $\left(18.5-23.9 \mathrm{~kg} / \mathrm{m}^{2}\right)$, overweight $\left(>23.9 \mathrm{~kg} / \mathrm{m}^{2}\right)$, before undergoing multivariable logistic regression analysis. After adjustments for gender and, age, a BMI $<18.5 \mathrm{~kg} / \mathrm{m}^{2}$ (underweight) was also found to be a risk factor of COPD
(Figure 2). Among adults aged 40 years and older, the risk of COPD doubled for every 10 additional years of age $(\mathrm{P}<0.05$, $\mathrm{OR}=2.29,95 \% \mathrm{CI}, 1.83-2.88$ ), whereas the risk of COPD for underweight patients (BMI $<18.5 \mathrm{~kg} / \mathrm{m}^{2}$ ) was 1.57 times higher than for those with a normal BMI $\left(18.5-23.9 \mathrm{~kg} / \mathrm{m}^{2}\right)$ $(\mathrm{P}<0.05, \mathrm{OR}=1.57,95 \% \mathrm{CI}, 1.01-2.44)$.

\section{Respiratory symptoms of COPD}

While $49.3 \%$ of COPD patients presented with respiratory symptoms, approximately half $(50.7 \%)$ were asymptomatic. The most common respiratory symptoms of COPD were chronic cough and phlegm (20.8\%) and breathlessness (33.1\%).

The differences between symptomatic and asymptomatic COPD patients are shown in Table 2. COPD patients with respiratory symptoms were of a higher average age $(69.5 \mathrm{vs}$. 67.2, $\mathrm{P}<0.05)$. This sub-population also displayed a higher rate of smoking $(38.8 \%$ vs. $25.9 \%, \mathrm{P}<0.05)$ and smoking pack years (12.1 vs. 7.1 pack-year, $\mathrm{P}<0.05)$ compared to those without respiratory symptoms. Furthermore, these patients also showed a stronger correlation with previous diagnoses and family history of chronic bronchitis $(16.6 \%$ vs. $10.8 \%, \mathrm{P}<0.05 ; 12.8 \%$ vs. $4.8 \%, \mathrm{P}<0.05)$. Lung function analysis between both groups revealed that COPD patients with respiratory symptoms often had more advanced GOLD staging than patients without symptoms (stage I $27.0 \%$ vs. $39.4 \%$, stage II $50.2 \%$ vs. $46.8 \%$, stage III $17.0 \%$ vs. $11.1 \%$, stage IV $5.8 \%$ vs. $2.7 \%, \mathrm{P}<0.05)$.

\section{Spirometry indices of COPD}

Spirometry indices such as $\mathrm{FEV}_{1}, \mathrm{FVC}, \mathrm{FEV}_{1}$ /predict, FVC/predict, $\mathrm{FEV}_{1} / \mathrm{FVC}, \mathrm{PEF}, \mathrm{FEF}_{25}, \mathrm{FEF}_{50}, \mathrm{FEF}_{75}$, and 
Table 2 Characteristics of symptomatic and asymptomatic COPD patients

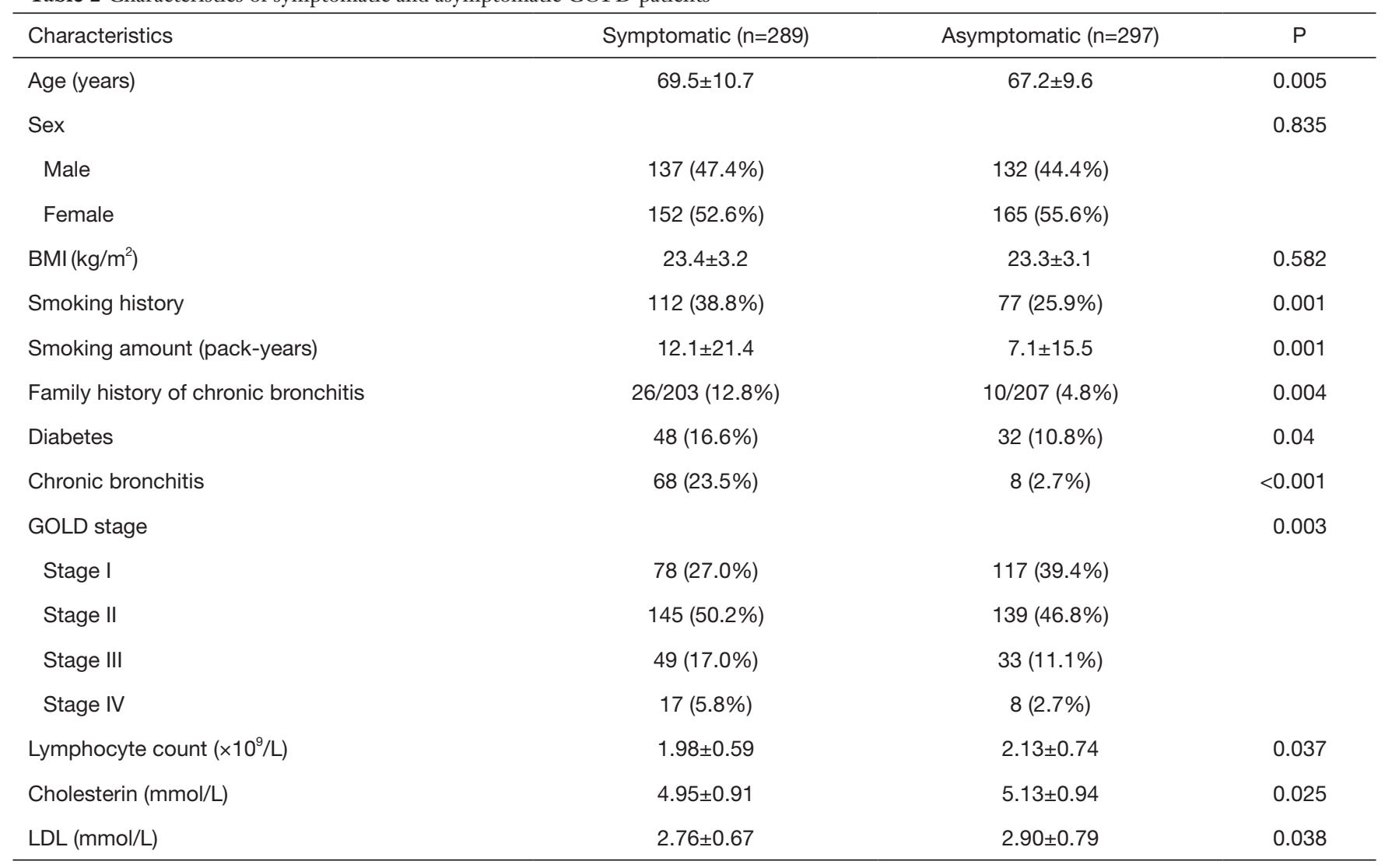

COPD, chronic obstructive pulmonary disease; BMI, body mass index; LDL, low density lipoprotein.

$\mathrm{FEF}_{25-75}$ were recorded. Analysis of the spirometry data suggested that $\mathrm{FEV}_{1}, \mathrm{FEV}_{1}$ /predict, $\mathrm{FVC}$ /predict, $\mathrm{FEV}_{1}$ / $\mathrm{FVC}, \mathrm{PEF}, \mathrm{FEF}_{25}, \mathrm{FEF}_{50}, \mathrm{FEF}_{75}$ and $\mathrm{FEF}_{25-75}$ were lower in the COPD group compared to the non-COPD group (Figure $3 A$ ). Moreover, these values decreased as GOLD staging increased in COPD group (Figure 3B). Symptomatic $\mathrm{COPD}$ patients displayed lower $\mathrm{FEV}_{1}, \mathrm{FVC}, \mathrm{FEV}_{1}$ /predict, FVC/predict, $\mathrm{PEF}, \mathrm{FEF}_{25}, \mathrm{FEF}_{50}, \mathrm{FEF}_{75}$, and $\mathrm{FEF}_{25-75}$ than asymptomatic COPD patients (Figure 3C), whereas the $\mathrm{FEV}_{1} / \mathrm{FVC}$ was similar between two groups. $\mathrm{FEV}_{1}, \mathrm{FVC}$, $\mathrm{FEV}_{1} / \mathrm{FVC}, \mathrm{PEF}, \mathrm{FEF}_{25}, \mathrm{FEF}_{50}, \mathrm{FEF}_{75}$, and $\mathrm{FEF}_{25-75}$ were higher among smokers than non-smokers (Figure 3D). However, these values were similar after age and gender adjusted were made.

\section{Discussion}

This is the first study which investigated the epidemiology and risk factors of COPD among a population aged 40 years and older in Suzhou. A prevalence of spirometry-diagnosed
COPD in this population was $12.4 \%$, and $12.3 \%$ in men and $12.5 \%$ in women. Age and underweight $\left(\mathrm{BMI}<18.5 \mathrm{~kg} / \mathrm{m}^{2}\right)$ were independent risk factors of COPD in our study. Approximately half of the COPD patients in Suzhou were asymptomatic, which highlighted the importance of spirometry analysis in health examinations.

The prevalence of COPD (GOLD stage II or higher) in the BOLD study was reported to be $10.1 \%$ (7). The 2017 Global Burden of Diseases, Injuries, and Risk Factors study reported that the number of COPD cases increased by $71.6 \%$ from 174.5 million in 2015 to 299.4 million in 2017 (8). In China, a study conducted by Zhong et al. reported that the prevalence of COPD in 40 years or older population was $8.2 \%$ between 2002 and 2004 (9) and increased to $13.7 \%$ between 2012 and 2015 (3). In other regions covered by the World Health Organization (WHO), the prevalence of COPD has also grown rapidly. In 2010, the pooled crude prevalence of COPD in people 30 years and older was highest in the USA (14.1\%), followed by the Eastern Mediterranean region (13.2\%), Europe (12.0\%), 

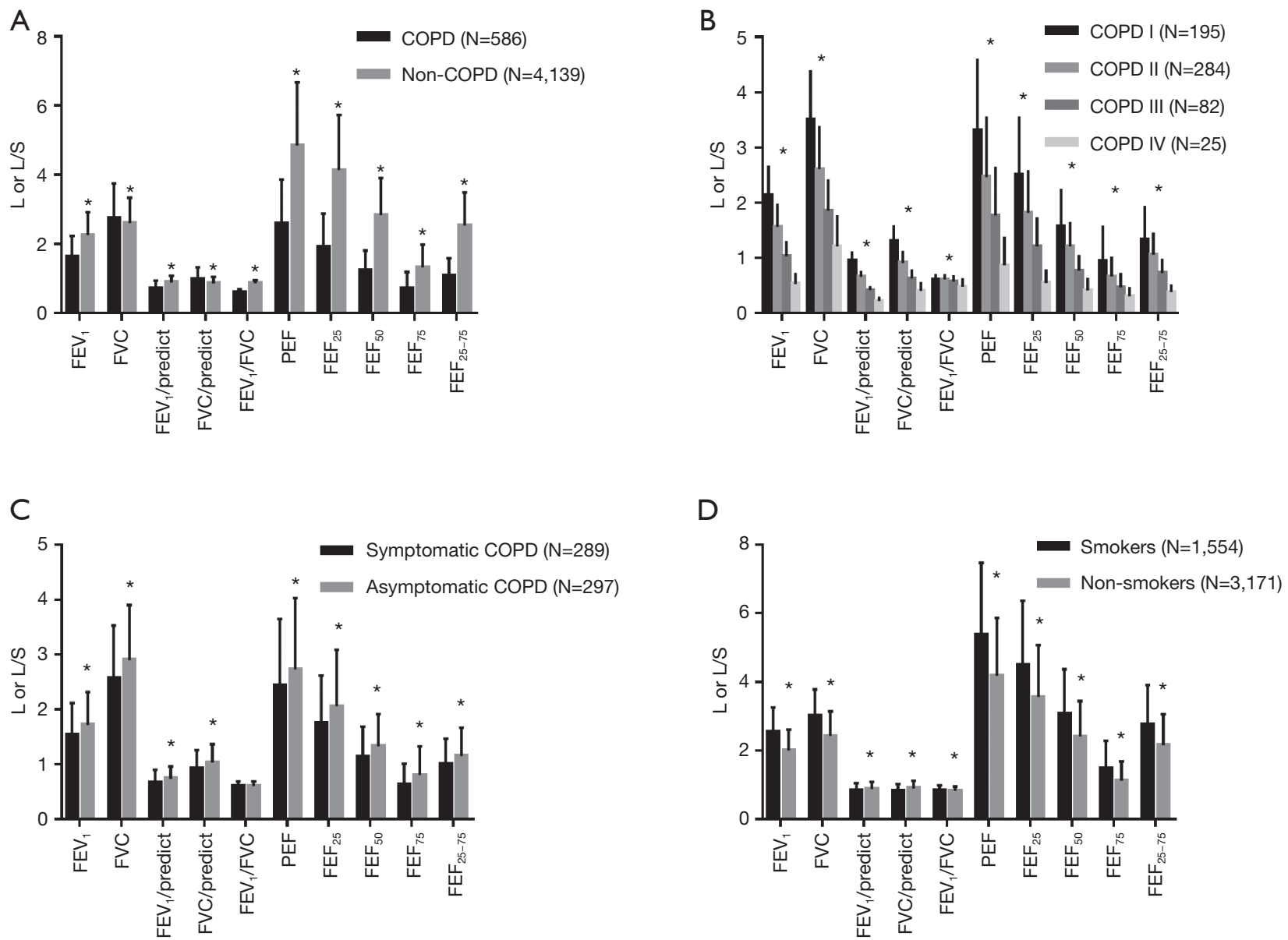

Figure 3 The comparison of spirometry index between different groups. Compared to non-COPD patients, COPD patients had lower values of $\mathrm{FEV}_{1}, \mathrm{FEV}_{1}$ /predict, FVC/predict, $\mathrm{FEV}_{1} / \mathrm{FVC}, \mathrm{PEF}, \mathrm{FEF}_{25}, \mathrm{FEF}_{50}, \mathrm{FEF}_{75}, \mathrm{FEF}_{25-75}$ (A). Values of FEV $\mathrm{FVC}_{1}, \mathrm{FEV}_{1} / \mathrm{predict}$, $\mathrm{FVC} /$ predict, $\mathrm{FEV}_{1} / \mathrm{FVC}, \mathrm{PEF}, \mathrm{FEF}_{25}, \mathrm{FEF}_{50}, \mathrm{FEF}_{75}$, and $\mathrm{FEF}_{25-75}$ decreased further as GOLD stage increased in the COPD group (B). Symptomatic COPD patients displayed lower $\mathrm{FEV}_{1}, \mathrm{FVC}, \mathrm{FEV}_{1}$ /predict, FVC/predict, $\mathrm{PEF}, \mathrm{FEF}_{25}, \mathrm{FEF}_{50}, \mathrm{FEF}_{75}$, and $\mathrm{FEF}_{25-75}$ than asymptomatic patients (C). Compared with non-smokers, smokers had higher $\mathrm{FEV}_{1}, \mathrm{FVC}, \mathrm{FEV}_{1} / \mathrm{FVC}, \mathrm{PEF} \mathrm{FEF}_{25}, \mathrm{FEF}_{50}, \mathrm{FEF}_{75}$ and $\mathrm{FEF}_{25-75}$ and lower $\mathrm{FEV}_{1}$ /predict, FVC/predict (D). *, $\mathrm{P}<0.05$. COPD, chronic obstructive pulmonary disease; GOLD, Global Initiative for Chronic Obstructive Lung Disease.

Africa (10.6\%), the Western Pacific region (10.0\%) and South East Asia (7.8\%) (2). Our study suggests that the prevalence of COPD among people 40 years and older in Suzhou was $12.4 \%$, which is higher than that in South East Asia (30 years and older), but lower than that in China reported by Wang et al. (3) (40 years and older).

Age is often listed as a risk factor of COPD, but it is unclear if this is attributed to increasing age, or if it is an artifact of cumulative exposure of smoke, particulate matter and biomass fuels throughout life (1). In our study, exposure to smoking, occupational and particulate matter were comparative between the COPD group and non-COPD group, demonstrating that age was an independent risk factor for COPD. Additionally, the risk of COPD doubled for every 10 additional years of age among adults 40 years and older. Fletcher-Peto curve and real-life studies indicated that $\mathrm{FEV}_{1}$ decline among COPD patients and healthy people accelerates more in older than in younger individuals $(10,11)$. The age-associated susceptibility to COPD may be attributed to structure changes, such as increases in cellular senescence, stem cell exhaustion, increased oxidative stress, alteration in the extracellular matrix, reduction in endogenous anti-ageing molecules and protective pathways (12). 
Low BMI, as a part of the Body-mass index, airflow Obstruction, Dyspnea, and Exercise (BODE) index, was proposed as a possible risk factor of COPD (13) and an independent indicator of poor prognosis (14). In our study, underweight $\left(<18.5 \mathrm{~kg} / \mathrm{m}^{2}\right)$ was also regarded as a risk factor for COPD, which increased the morbidity by 1.57 times. To determine if this phenomenon contributed to COPD or was a result of this disease, Zhou and his colleagues (15) conducted a cohort study, which indicated that low BMI was not only a systemic consequence of COPD but also an important risk factor. Improving BMI may be a possible intervention measure to reduce the incidence of COPD, which requires further investigation.

Most studies reported a higher prevalence of COPD in men than in women $(3,9)$. However, a recent study in developing countries has shown a similar prevalence in men and women (16). In our study, 2,188 men and 2,537 women were diagnosed as COPD, with the gender ratio showing no difference between the COPD group and the non-COPD group. In addition, biomass exposure $(17,18)$ and passive smoke (19), which were reported as possible risk factors for COPD in women, were not investigated in this study.

Approximately half of the COPD patients were asymptomatic in our study, despite other reports which suggested that these patients constituted of more than onethird of COPD patients $(9,20)$. Asymptomatic patients in our study were younger, smoked less, and displayed less severe GOLD staging. Although asymptomatic COPD patients did not present with chronic activity-related dyspnea, their cardiopulmonary performance was worse compared to healthy controls (21). In one study, early intervention with tiotropium was found to ameliorated the annual decline of the $\mathrm{FEV}_{1}$ in patients at GOLD stage I or II of COPD (22). Although spirometry is only recommended in patients with symptoms and/or with risk factors by GOLD (1), we advocate spirometry screening for patients aged 40 years and older because of the high percentage of asymptomatic patients and improved outcomes of early treatment.

Spirometry provides the most definitive measure for the diagnosis of COPD. The study showed that $\mathrm{FEV}_{1}, \mathrm{FVC}$, $\mathrm{FEV}_{1} /$ predict, FVC/predict, $\mathrm{FEV}_{1} / \mathrm{FVC}, \mathrm{PEF}, \mathrm{FEF}_{25}$, $\mathrm{FEF}_{50}, \mathrm{FEF}_{75}$ and $\mathrm{FEF}_{25-75}$ were lower in the COPD group than in the non-COPD group. Moreover, these values continued to decrease as the GOLD stage progressed. This may be attributed to the resistance of small airways and the weakened respiratory muscle strength $(23,24)$. Symptomatic COPD patients also displayed lower $\mathrm{FEV}_{1}$,
FVC, FEV ${ }_{1}$ predict, FVC/predict, PEF, $\mathrm{FEF}_{25}, \mathrm{FEF}_{50}, \mathrm{FEF}_{75}$, and $\mathrm{FEF}_{25-75}$ compared to asymptomatic COPD patients. However, the $\mathrm{FEV}_{1} / \mathrm{FVC}$ values were similar between the groups. In some COPD patients, respiratory symptoms might precede the development of airflow limitation (25), but in others, it could fall behind the spirometry change by many years (16). Cigarette smoking is the most significant risk factor for COPD, and induces more respiratory symptoms and greater $\mathrm{FEV}_{1}$ decline (1). However, smokers in our study showed higher $\mathrm{FEV}_{1}, \mathrm{FVC}, \mathrm{FEV}_{1} / \mathrm{FVC}, \mathrm{PEF}, \mathrm{FEF}_{25}$, $\mathrm{FEF}_{50}, \mathrm{FEF}_{75}$, and $\mathrm{FEF}_{25-75}$ but lower $\mathrm{FEV}_{1}$ /predicted and FVC/predicted than non-smokers. This reflects the larger proportion of male smokers, who have a higher absolute value of $\mathrm{FEV}_{1}$ than female participants. After adjustments were made for age and sex, the values were similar between two groups, which may be related to the following factors: firstly, exposure to passive smoke was not recorded and analyzed; secondly, other risk factors such as genetic factors and indoor air pollution may also influence lung function.

\section{Limitations}

First, typical to most cross-sectional studies, this study could not exclude potential recall bias. Second, the data for passive smoking and atmospheric particle exposure were not acquired, but are reported as important risk factors of COPD. Finally, compared to the lower limit of normal (LLN) criteria, the GOLD criteria $(\mathrm{FEV} 1 / \mathrm{FVC}<0.7)$ may over-diagnose about 28\% COPD among elders aged 65 and older, but we still chose the GOLD criteria for its efficiency in identifying high risk population.

\section{Conclusions}

This cross-sectional study showed that the prevalence of spirometry-diagnosed COPD in Suzhou was $12.4 \%$ in populations aged 40 and older according to GOLD criteria. Increasing age and underweight $\left(\mathrm{BMI}<18.5 \mathrm{~kg} / \mathrm{m}^{2}\right)$ were the main risk factors. Additionally, half the patients were found to be asymptomatic. The study highlighted COPD as a significant public health problem, indicating a need for early detection and prevention.

\section{Acknowledgments}

Funding: This work was supported by the Suzhou Municipal Commission of Health and Family Planning (No. LCX201712). 


\section{Footnote}

Data Sharing Statement: Available at http://dx.doi. org/10.21037/jtd-20-1616

Conflicts of Interest: All authors have completed the ICMJE uniform disclosure form (available at http://dx.doi. org/10.21037/jtd-20-1616). Dr. XX reports grants from the Suzhou Municiple Commission of Health and Family Planning, during the conduct of the study. The other authors have no conflicts of interest to declare.

Ethical Statement: The authors are accountable for all aspects of the work in ensuring that questions related to the accuracy or integrity of any part of the work are appropriately investigated and resolved. The study was conducted in accordance with the Declaration of Helsinki (as revised in 2013). The study protocol was approved by the ethics review committee of the affiliated Suzhou Hospital of Nanjing Medical University (K2018013) and informed consent was taken from all individual participants.

Open Access Statement: This is an Open Access article distributed in accordance with the Creative Commons Attribution-NonCommercial-NoDerivs 4.0 International License (CC BY-NC-ND 4.0), which permits the noncommercial replication and distribution of the article with the strict proviso that no changes or edits are made and the original work is properly cited (including links to both the formal publication through the relevant DOI and the license). See: https://creativecommons.org/licenses/by-nc-nd/4.0/.

\section{References}

1. Global Strategy for the Diagnosis, Management, and Prevention of Chronic Obstructive Pulmonary Disease (2018 Report). Available online: https://goldcopd.org

2. Adeloye D, Chua S, Lee C, et al. Global and regional estimates of COPD prevalence: Systematic review and meta-analysis. J Glob Health 2015;5:020415.

3. Wang C, Xu J, Yang L, et al. Prevalence and risk factors of chronic obstructive pulmonary disease in China (the China Pulmonary Health [CPH] study): a national cross-sectional study. Lancet 2018;391:1706-17.

4. GBD 2017 DALYs and HALE Collaborators. Global, regional, and national disability-adjusted life-years (DALYs) for 359 diseases and injuries and healthy life expectancy (HALE) for 195 countries and territories,
1990-2017: a systematic analysis for the Global Burden of Disease Study 2017. Lancet 2018;392:1859-922.

5. Zhu B, Wang Y, Ming J, et al. Disease burden of COPD in China: a systematic Review. Int J Chron Obstruct Pulmon Dis 2018;13:1353-64.

6. Standardization of Spirometry, 1994 Update. American Thoracic Society. Am J Respir Crit Care Med 1995;152:1107-36.

7. Buist AS, McBurnie MA, Vollmer WM, et al. International variation in the prevalence of COPD (the BOLD Study): a population-based prevalence study. Lancet 2007;370:741-50.

8. GBD 2017 Disease and Injury Incidence and Prevalence Collaborators. Global, regional, and national incidence, prevalence, and years lived with disability for 354 diseases and injuries for 195 countries and territories, 1990-2017: a systematic analysis for the Global Burden of Disease Study 2017. Lancet 2018;392:1789-858.

9. Zhong N, Wang C, Yao W, et al. Prevalence of chronic obstructive pulmonary disease in China: a large, population-based survey. Am J Respir Crit Care Med 2007;176:753-60.

10. Fletcher C, Peto R. The natural history of chronic airflow obstruction. Br Med J 1977;1:1645-8.

11. Kim SJ, Lee J, Park YS, et al. Age-related annual decline of lung function in patients with COPD. Int $\mathrm{J}$ Chron Obstruct Pulmon Dis 2015;11:51-60.

12. Mercado N, Ito K, Barnes PJ. Accelerated ageing of the lung in COPD: new concepts. Thorax 2015;70:482-9.

13. Harik-Khan RI, Fleg JL, Wise RA. Body mass index and the risk of COPD. Chest 2002;121:370-6.

14. Celli BR, Cote CG, Marin JM, et al. The body-mass index, airflow obstruction, dyspnea, and exercise capacity index in chronic obstructive pulmonary disease. $\mathrm{N}$ Engl J Med 2004;350:1005-12.

15. Zhou Y, Wang D, Liu S, et al. The Association between BMI and COPD: The Results of Two Population-based Studies in Guangzhou, China. COPD 2013;10:567-72.

16. Landis SH, Muellerova H, Mannino DM, et al. Continuing to Confront COPD International Patient Survey: methods, COPD prevalence, and disease burden in 2012-2013. Int J Chron Obstruct Pulmon Dis 2014;9:597-611.

17. Sana A, Somda SMA, Meda N, et al. Chronic obstructive pulmonary disease associated with biomass fuel use in women: a systematic review and meta-analysis. BMJ Open Respir Res 2018;5:e000246. 
18. Zhou Y, Zou Y, Li X, et al. Lung function and incidence of chronic obstructive pulmonary disease after improved cooking fuels and kitchen ventilation: a 9-year prospective cohort study. PLoS Med 2014;11:e1001621.

19. Yin P, Jiang CQ, Cheng KK, et al. Passive smoking exposure and risk of COPD among adults in China: the Guangzhou Biobank Cohort Study. Lancet 2007;370:751-7.

20. Çolak Y, Afzal S, Nordestgaard BG, et al. Prognosis of asymptomatic and symptomatic, undiagnosed COPD in the general population in Denmark: a prospective cohort study. Lancet Respir Med 2017;5:426-34.

21. Soumagne T, Laveneziana P, Veil-Picard M, et al. Asymptomatic subjects with airway obstruction have

Cite this article as: Yan X, Xu L, Shi B, Wang H, Xu X, Xu G. Epidemiology and risk factors of chronic obstructive pulmonary disease in Suzhou: a population-based cross-sectional study. J Thorac Dis 2020;12(10):5347-5356. doi: 10.21037/jtd-20-1616 significant impairment at exercise. Thorax 2016;71:804-11.

22. Zhou Y, Zhong NS, Li X, et al. Tiotropium in Early-Stage Chronic Obstructive Pulmonary Disease.N Engl J Med 2017;377:923-35.

23. Crisafulli E, Pisi R, Aiello M, et al. Prevalence of SmallAirway Dysfunction among COPD Patients with Different GOLD Stages and Its Role in the Impact of Disease.

Respiration 2017;93:32-41.

24. Leitão Filho FS, Hang Chen H, Ngan DA, et al. Current methods to diagnose small airway disease in patients with COPD. Expert Rev Respir Med 2016;10:417-29.

25. Woodruff PG, Barr RG, Bleecker E, et al. Clinical Significance of Symptoms in Smokers with Pulmonary Function. N Engl J Med 2016;374:1811-21. 